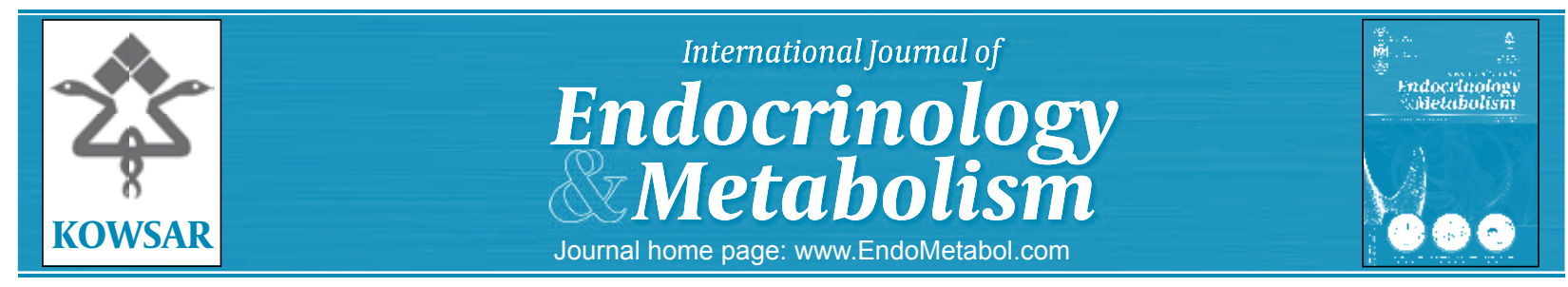

\title{
Assessment of Influencing Factors on Outcomes of Transsphenoidal Surgery in Acromegalic Patients
}

\author{
Zohreh Annabestani ${ }^{1}$, Mohammad Reza Mohajeri-Tehrani ${ }^{{ }^{*}}$, Ozra Tabatabaie-Malazy ${ }^{1}$, \\ Shahrzad Mohseni ${ }^{1}$, Ramin Heshmat ${ }^{1}$, Mohammad Karim Shahrzad ${ }^{1}$, Bagher Larijani ${ }^{1}$ \\ ${ }^{1}$ Endocrinology and Metabolism Research Center, Tehran University of Medical Sciences, IR Iran
}

\begin{tabular}{l} 
A R T I C L E I N F O \\
Article type: \\
Original Article \\
\hline Article history: \\
Received: 05 Jul 2011 \\
Revised: 10 Aug 2011 \\
Accepted: 20 Aug 2011 \\
\hline
\end{tabular}

Keywords:

Influencing Factor

Outcome

Acromegaly \begin{abstract}
A B S T R A C T
Background: Transsphenoidal surgery (TSS) is the most effective treatment for acromegalic patients, and two major factors that have been suggested as useful predictors in assessing this therapy's success are: tumor size and preoperative basal growth hormone (GH) levels

Objectives: The aim of this study was to illustrate the relationship between some predictor factors and transsphenoidal surgery (TSS) outcomes and its remission rate.

Patients and Methods: A total of 20 patients underwent TSS by 4 neurosurgeons in 4 university hospitals in Tehran and were followed up for 1 year. An oral glucose tolerance test was performed at 1 week after surgery and then 3, 6, and 12 months after surgery. Moreover, Insulin Growth Factor-1(IGF-1) was measured at 6 and 12 months after surgery.

Results: Initial remission was observed in 7 (35\%) patients with a recurrence rate of $10 \%$. The nonresponse rate was $55 \%$. The analysis showed a significant relationship between IGF-1 and surgery outcome in the cured patients at 6 months after surgery $(P=0.005)$. No significant statistical relationship was found between tumor size and the TSS outcome $(P=0.696)$.

Conclusions: Given the high failure and recurrence rates following TSS in Iran, it seems important to pay more attention to diagnosing the disease earlier and improving surgical methods.
\end{abstract}

Copyright $\odot 2011$ Kowsar M.P. Co. All rights reserved.

- Implication for health policy/practice/research/medical education:

Recurrence rate of acromegaly after TSS is fairly high in Iran. It may be due to latency of diagnosis and loss of patient follow up after surgery. Therefore practitioners should be more pay attention to these patients after surgery.

- Please cite this paper as:

Annabestani Z, Mohajeri-Tehrani MR, Tabatabaie-Malazy O, Mohseni S, Heshmat R, Shahrzad MK, et al. Assessment of Influencing Factors on Outcomes of Transsphenoidal Surgery in Acromegalic Patients. Int JEndocrinol Metab. 2011;9(4):360-3. DOI:10.5812/Kowsar.1726913X.2125

\section{Background}

Transsphenoidal surgery (TSS) is the most effective treatment for acromegalic patients, and a large number of factors have been suggested as useful predictors in assessing this therapy's success. Two of these predictors are tumor size (1) and preoperative basal growth hormone

* Corresponding author: Mohammad Reza Mohajeri Tehrani, 5th Floor, Shariati Hospital, North Kargar Avenue, Endocrinology and Metabolism Research Center, Tehran, IR Iran. Tel: +98-2188220037, Fax:+98-2188220052, E-Mail: mrmohajeri@tums.ac.ir

DOI: 10.5812/Kowsar.1726913X.2125

Copyright $\odot 2011$ Kowsar M.P.Co. All rights reserved.
(GH) levels (2), both of which are associated with the outcome of surgery and the need for further treatment. The biochemical control of acromegaly is determined by GH (both fasting and after an oral glucose tolerance test [OGTT]) and insulin growth factor 1 (IGF-1) levels. The therapeutic control is achieved if GH nadir is $<1.0 \mu \mathrm{g} / \mathrm{L}$ in the OGTT and IGF-1 is within the normal range adjusted for age and sex (3-6).

\section{Objectives}

In a study in 2006, Abbassion et al. found that, in developing countries, early diagnosis and an expert pituitary surgeon are important factors in reducing mortality and 
increasing the likelihood of recuperation. Still, there is a dearth of data on the outcomes acromegaly management in Iran. In this prospective study, we evaluated 20 patients with newly diagnosed acromegaly who underwent TSS between 2007 and 2009 to determine which preoperative factors could significantly influence longterm surgical outcomes. In addition, we sought to determine whether nadir GH or IGF-1 was a useful outcome predictor and also establish recurrence and remission rates after surgery.

\section{Patients and Methods}

Between May 2007 and December 2009, a total of 20 patients comprising 10 females and 10 males at a median age of 35 years (range $=22-57$ years) underwent TSS for pituitary tumors by four neurosurgeons in four university hospitals in Tehran. The inclusion criterion was established acromegaly with hormonal assessment consisting of GH $>1 \mathrm{ng} / \mathrm{dL}$; means = lack of GH suppression following glucose tolerance test; IGF-1 $>$ the normal range for the patient's age; and a corresponding patient matched by sex. Previous TSS or radiotherapy and related medications were the exclusion criteria in this study. Ten patients had macroadenomas ( $\geq 10 \mathrm{~mm})$, and 10 patients had microadenomas ( $<10 \mathrm{~mm})$.

Informed consent was obtained from all participants, and the Ethical Committee of the Endocrinology and Metabolism Research Center (EMRC) approved this study. All of the patients had pathological confirmation of a GH-secreting adenoma. The presence of a pituitary adenoma was confirmed by MRI of the sellar region, and the size of the adenoma was recorded. The duration of the disease and remission periods were estimated according to acromegalic signs and symptoms based on the patient's history and medical records. Table 1 depicts the clinical characteristics of the patients, and Table 2 shows the associated signs and symptoms of the participants with acromegaly. During the first week after TSS, all patients had a 75-gram oral glucose tolerance test (OGTT), and their blood samples were obtained at baseline and then at 60,90 , and 120 minutes. The OGTT was repeated at 3, 6, and 12 months after TSS. Hormonal assessment was performed for IGF-1 and PRL at baseline (preoperative) and then repeated at 6 and 12 months after surgery. A visual field assessment was carried out before TSS and subsequently at 6 and 12 months after surgery. The subjects were interviewed each month after TSS about recurrent symptoms such as headache, blurred vision, and other important complaints. All the laboratory tests were performed in the EMRC of Shariati Hospital. Endocrinological remission or cure criteria were defined by a post-OGTT GH value of less than $1.0 \mathrm{ng} / \mathrm{mL}$ and a normal IGF-1 level for that patient's age. Patients who did not meet both criteria were considered to have a persistent, active disease. The GH and IGF-1 levels were measured via an immunoradiometric assay (IRMA) in the EMRC laboratory. The data analysis was conducted using SPSS version 15 . The analysis of the categorical variables was conducted with Fisher exact tests or chi-square tests. A probability $P$ value of less than .05 was considered statistically significant.

\section{Results}

The mean preoperative GH was $37.6 \pm 30.4 \mathrm{ng} / \mathrm{dL}$. The patients were divided into 3 groups: (1) the cured group, which consisted of 7 patients who had GH $<1 \mathrm{ng} / \mathrm{mL}$ during the 12-month follow-up period after TSS; (2) the recurrent group, which consisted of 2 patients who had GH levels $<1 \mathrm{ng} / \mathrm{mL}$ during the 1 st week after TSS but increased to more than $1 \mathrm{ng} / \mathrm{mL}$ during 6 months after surgery; and (3) the nonresponsive group, which consisted of 11 patients whose GH level was $>1 \mathrm{ng} / \mathrm{mL}$ in the OGTTtest during the 1st week after TSS. An initial remission following TSS was observed in 7 (35\%) patients with a recurrence rate of $10 \%$, and the nonresponse rate was $55 \%$.

A significant relationship was found in the cured group between IGF-1 at 6 months after surgery, and the outcome of the surgery $(P=0.005)$. However, no statistically significant relationship was detected between the tumor size and the TSS outcome $(P=0.696)$. The mean time interval between the occurrence of acromegalic-specific symptoms and the date of diagnosis was 2.4 years (range $=0.3$ to 5 years). Factors affecting the remission rate are demonstrated in Table 3. Nine patients were on medical treatment after TSS (Table 4). Some surgical complications occurred that required long-term medical therapy, such as diabetes insipidus in 5 (25\%) patients. There were also complications of pneumocephalus and meningitis

Table 1. Preoperative Characteristics of the 20 Patients With Acromegaly in Iran

\begin{tabular}{lll}
\hline & Mean \pm SD & Range \\
\hline Age at diagnosis, y & $35.8 \pm 10$ & $22-57$ \\
Duration of symptom , y & $2.4 \pm 1.0$ & $0.3-5$ \\
Growth hormone, $\mathrm{ng} / \mathrm{mL}$ & $37.6 \pm 30$ & $1-110$ \\
IGF-I, nmol/L & $1125.9 \pm 553$ & $421-2170$ \\
PRL, nmol/L & $59.4 \pm 141$ & $2-541$ \\
BMI, $\mathrm{kg} / \mathrm{m}^{2}$ & $28.03 \pm 5$ & $19-40$ \\
BP, $\mathrm{mmHg}$ & $118 \pm 15$ & $100-160$ \\
FBS, $\mathrm{mg} / \mathrm{dL}$ & $101 \pm 17$ & $70-128$ \\
\hline
\end{tabular}

\begin{tabular}{lc}
\hline Table 2. Associated Symptoms and Signs of the 20 Acromegalic Patients \\
\hline & Number of Cases, No. $(\mathbf{n}=\mathbf{2 0})$ \\
\hline Diabetes mellitus & 0 \\
Headache & 9 \\
Visual disturbance & 5 \\
Artheralgia & 1 \\
Hypertension & 2 \\
Hyperprolactinemia & 1 \\
\hline
\end{tabular}




\begin{tabular}{ll}
\hline \multicolumn{2}{l}{ Table 3. Univariate Analysis of Factors Affecting Remission } \\
\hline Factors & P values \\
\hline Tumor size & 0.696 \\
Preoperative GH-level & 0.462 \\
Preoperative IGF-1 level & 0.455 \\
Postoperative IGF-1 level (6 months) & 0.05 \\
\hline
\end{tabular}

\begin{tabular}{ll}
\hline \multicolumn{2}{l}{ Table 4. TSS Outcome in the Acromegalic Patients one Year After TSS } \\
\hline No. (\%) \\
\hline Cure (remission) & $7(35)$ \\
Recurrent & $2(10)$ \\
Non- Response & $11(55)$ \\
Radiotherapy & $2(10)$ \\
Second Surgery & $1(1)$ \\
Mortality & $0(0)$ \\
\hline
\end{tabular}

in 1 patient after the second surgery. Finally, postoperative cerebrospinal fluid leakage occurred in 1 patient.

\section{Discussion}

We analyzed the surgical results of TSS in 20 acromegalic patients. Using the consensus statement for biochemical remission of acromegaly (7), we had a surgical remission rate of $35 \%$ for acromegaly without mortality. Generally, the recurrence rate of acromegaly is extremely rare when cure criteria are used. The high recurrence rate in our study may have been due to the fact that the GH levels after surgery did not reach the nadir level.

Our analysis of the prognostic factors showed that the tumor size and the outcome of the surgery did not have a significant relationship with each other; this may have been due to the small size of our patient population. TSS is the best chance for an immediate reduction in GH levels. Indeed, this surgical modality may achieve posttreatment GH levels of less than $5 \mathrm{mu} / \mathrm{L}(2 \mathrm{ng} / \mathrm{mL})$. Some researchers believe that the post-OGTT nadir GH value is a very useful indicator of activity in acromegaly in that it can evaluate GH secretory dynamics (8). The failure to achieve our treatment target could have been related to latency in diagnosis, inexperienced surgeons, and multiple numbers of surgeons, among other possible factors. Evidence (9-12) suggests that IGF-1 measurements could be used to monitor disease activity overall and predict long-term outcomes in acromegaly; $(13,14)$ accordingly, we believe that the measurements obtained in the week after surgery could reflect surgical efficacy. Using normalization of IGF-1 levels following surgery as the definition of cure, we had a cure rate of $35 \%$ in our patients. We found the basal preoperative serum IGF-1, which was correlated poorly with tumor size, was unrelated to the surgical outcome, but IGF1 after 6 months was significantly correlated with the TSS outcome. In a considerable number of patients, TSS is generally associated with an improvement of vision; in our study, however, only 2 patients who had visual disturbances showed improvement after TSS.

First and foremost among the limitations of this study is the small sample size. More in-depth assessments of factors influencing the remission rate of acromegaly after TSS should be undertaken with larger patient populations. Two other limitations were that we used 4 surgeons in the study and we were unable to omit the confounding effect of surgeon experience.

In conclusion, the failure and recurrence rates after TSS are relatively high in Iran, probably because of latency in diagnosis and inexperience of surgeons. So, pay attention to early diagnosis of disease and improvement in methods of surgery seems necessary. We suggest that serum GH levels after OGTT in conjunction with IGF-1 be evaluated to better assess patients' responses to TSS.

\section{Acknowledgments}

We wish to thank our patients, without whose invaluable cooperation this study would not have been possible.

\section{Financial Disclosure}

None declared.

\section{Funding/Support}

None declared.

\section{References}

1. Osman IA, James RA, Chatterjee S, Mathias D, Kendall-Taylor P. Factors determining the long-term outcome of surgery for acromegaly. QJM. 1994;87(10):617-23.

2. Bush ZM, Vance ML. Management of acromegaly: is there a role for primary medical therapy? Rev Endocr Metab Disord. 2008;9(1):83-94.

3. Abbassioun K, Amirjamshidi M, Mehrazin A, Khalatbary I, Keynama $\mathrm{M}$, Bokai $\mathrm{H}$, et al. A prospective analysis of 151 cases of patients with acromegaly operated by one neurosurgeon: a follow-up of more than 23 years. Surg Neurol. 2006;66(1):26-31; discussion

4. De P, Rees DA, Davies N, John R, Neal J, Mills RG, et al. Transsphenoidal surgery for acromegaly in wales: results based on stringent criteria of remission. J Clin Endocrinol Metab. 2003;88(8):3567-72.

5. Gullu S, Keles H, Delibasi T, Tonyukuk V, Kamel N, Erdogan G. Remission criteria for the follow-up of patients with acromegaly. EurJEndocrinol. 2004;150(4):465-71.

6. Ludecke DK, Abe T. Transsphenoidal microsurgery for newly diagnosed acromegaly: a personal view after more than 1,000 operations. Neuroendocrinology. 2006;83(3-4):230-9.

7. Nomikos P, Buchfelder M, Fahlbusch R. The outcome of surgery in 668 patients with acromegaly using current criteria of biochemical 'cure'. Eur J Endocrinol. 2005;152(3):379-87.

8. Melmed S, Jackson I, Kleinberg D, Klibanski A. Current treatment guidelines for acromegaly. J Clin Endocrinol Metab. 1998;83(8):2646-52.

9. Barkan AL, Beitins IZ, Kelch RP. Plasma insulin-like growth factor-I/somatomedin-C in acromegaly: correlation with the degree of growth hormone hypersecretion.J Clin Endocrinol Metab. 1988;67(1):69-73.

10. Dobrashian RD, O'Halloran DJ, Hunt A, Beardwell CG, Shalet SM. Relationships between insulin-like growth factor-1 levels 
and growth hormone concentrations during diurnal profiles and following oral glucose in acromegaly. Clin Endocrinol (Oxf). 1993;38(6):589-93.

11. Ho KY, Weissberger AJ. Characterization of 24-hour growth hormone secretion in acromegaly: implications for diagnosis and therapy. Clin Endocrinol (Oxf). 1994;41(1):75-83.

12. Melmed S, Colao A, Barkan A, Molitch M, Grossman AB, Kleinberg D, et al. Guidelines for acromegaly management: an update. $J$
Clin Endocrinol Metab. 2009;94(5):1509-17.

13. Giustina A, Barkan A, Casanueva FF, Cavagnini F, Frohman L, Ho $\mathrm{K}$, et al. Criteria for cure of acromegaly: a consensus statement. J Clin Endocrinol Metab. 2000;85(2):526-9.

14. Swearingen B, Barker FG, Katznelson L, Biller BM, Grinspoon S, Klibanski A, et al. Long-term mortality after transsphenoidal surgery and adjunctive therapy for acromegaly. J Clin Endocrinol Metab. 1998;83(10):3419-26. 